\title{
The application of micro-lesson in optics teaching
}

Suzhen Yuan, Xuefeng Mao, Yongle Lu, Yan Wang, Yuan Luo

Suzhen Yuan, Xuefeng Mao, Yongle Lu, Yan Wang, Yuan Luo, "The application of micro-lesson in optics teaching," Proc. SPIE 10452, 14th Conference on Education and Training in Optics and Photonics: ETOP 2017, 1045211 (16 August 2017); doi: 10.1117/12.2269404

SPIE Event: 14th Conference on Education and Training in Optics and Photonics, ETOP 2017, 2017, Hangzhou, China 


\title{
The Application of Micro-lesson in Optics Teaching
}

\author{
Suzhen Yuan*, Xuefeng Mao, Yongle Lu, Yan Wang, Yuan Luo \\ College of Opto Electronic Engineering, Chongqing University of Posts and Telecommunications, \\ Chongqing 400065, China
}

\begin{abstract}
In order to improve students' ability on self-study, this paper discusses the application of micro-lesson as a supplementary way in the course of optics teaching. Both geometric optics and wave optics require a lot of demos, fortunately, micro-lesson just meets this requirement. Nowadays, college education focuses on quality education, so the new nurture scheme of most universities shortened the class hours. However, the development of students and the social needs also require students to have a solid foundation. The effective way to solve this contradiction is to improve the efficiency of classroom teaching and provide the repeatable learning form, micro-lesson.
\end{abstract}

Keywords: Micro-lesson, quality education, study efficiency

\section{INTRODUCTION}

Nowadays, education informationization has become an important content of China's education reform. The application of information technology in education field led to the micro-lesson. This is the new attempt on the combination of school education and the information technology, which provides a new way of the development of modern education. Micro-lesson is developed firstly in San Juan College in Farmington, New Mexico [1]. Then, many other colleges and universities abroad are integrating the micro-lesson into formal coursework, e.g. at the University of Illinois at UrbanaChampaign, students in Animal Science learn the appropriate technique for milking cows. Previously, the professor taught this skill by lecturing as he demonstrated the procedure, but as class size grew, some students could not see clearly. A micro-lesson and demo, delivered via iPad, through which way can make sure every student can see the process clearly. In China's college education, micro-lesson is used in the practice of teaching, and has made the preliminary results in many areas [2]. Surveys have indicated that particularly in large number student courses, students appreciate the flexibility of micro-lessons, which allow them to review the course conveniently.

\section{OVERVIEW OF MICRO-LESSON}

What is micro-lesson? Reference [1] gives the definition in the first paragraph. A micro-lesson is a short recorded audio or video presentation on a single, tightly defined topic. It is usually used as a component of online or face-to-face teaching. The time of the micro-lesson is often controlled at about 10 minutes. Some researches support that the microlesson should be controlled in about 60 seconds to three minutes [3]. Instructors at other colleges, such as York University, in Toronto, have experimented with lectures that last about 20 minutes. They found that students can quickly grow bored watching a talking head on their computer screens. But San Juan's 60-second lecture may take the shrinkinglecture trend the furthest. In my opinion, in optical teaching, about three or five minutes is much more appropriate. Micro-lesson takes the short video as the main carrier in accordance with the requirements of education ministry new curriculum reform. The purpose of the micro-lesson is clear; it mainly records a difficult factor knowledge point or the process of teaching and learning activities [4]. The schematic diagram of the micro-lesson is shown in Fig.1.

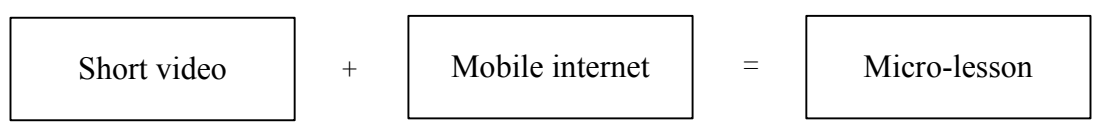

Fig. 1 The schematic diagram of the micro-lesson

As shown in Fig. 1, the micro-lesson is the combination of short video and the mobile internet. The video is generally a knowledge point or an demo of experiment, but also needs a series of related materials, exercises, test, discussion, and teaching feedback [5,6].Micro-lesson has the following characteristics as shown in Fig. 2: 1) The change of teaching model. Traditional teaching attentions to the transfer of knowledge, all the teaching activities happen in class

14th Conference on Education and Training in Optics and Photonics: ETOP 2017, edited by Xu Liu,

Xi-Cheng Zhang, Proc. of SPIE Vol. 10452, 1045211 - () 2017 ICO, IEEE, OSA, SPIE

CCC code: $0277-786 \mathrm{X} / 17 / \$ 18 \cdot$ doi: $10.1117 / 12.2269404$ 
time. Micro-lesson changes this into students-centered and question-centered model. 2) The change of teachers' role. Micro-lesson changes teacher-centered to teacher-guided. In class time, teacher's task is to deal with problems raised by students and make proper explanation about some knowledge hard to learn but not gushing over knowledge. 3) The change of students' role. In traditional teaching, students are passive knowledge receiver. Micro-lesson makes students the active learner. Before class, student can get knowledge themselves through micro-lesson on line or other tools. When they meet questions they can discuss them with other students before class or with teachers in class. This kind of learning can obtain good effect. They can find problems before class and solve them before or in class.

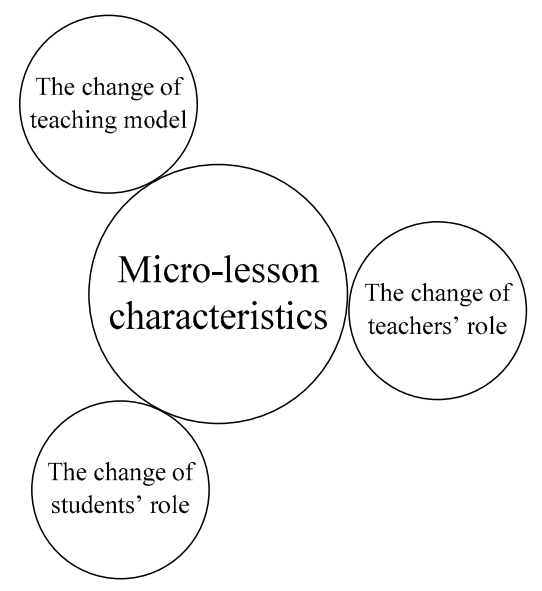

Fig. 2 The characteristics of micro-lesson

\section{ANALYSIS OF OPTICS TEACHING}

Optic is an important basic subject of physics, and also is an important pillar of the fast development of modern science and technology. However, optics teaching meets several problems with the implementation of teaching reform in China.

Firstly, contradiction between the curriculum capacity and the shorten class hours. Optics curriculum usually includes geometrical optics, wave optics and modern optics. The content is massive, tough and complicated. Nowadays, college education focuses on quality education, so the new nurture scheme of most universities shortened the class hours, including optics curriculum. However, the development of students and the social needs require students to have a solid foundation. Teachers need to balance traditional optics and modern optics; Teachers need to lecture on basic conception, basic physics thoughts and basic skills; Teachers should pay attention to important and difficult points, let students know how to think about problems and how to solve problems. In limited class hours, much knowledge is needed to be taught, so teachers are expect to reform the teaching form.

Secondly, theory and experiment are related closely. In optics teaching, many theories are concluded from experiment phenomenon. But in most cases, theory is the first and followed with the experiment. Thus, it is hard for students to understand these theories. They cannot really understand these theories and cannot form the visual impression, but just memorize these theorems mechanically. If the experiment and the theory proceed simultaneously, it will be a very interesting content, but this effect cannot be achieved in traditional optics teaching. lesson.

The above two aspects is the problems in optics teaching. These problems will be solved when we adopt micro-

\section{THE APPLICATION OF MICRO-LESSON IN OPTICS TEACHING}

Micro-lesson can meet students' individuation learning. They can watch videos before the class, in the class or after the class, so they can learn the difficult point repeatedly. Micro-lesson is an important complement to the traditional classroom teaching. Based on the characteristic of optics teaching, the application of micro-lesson in optics teaching reflected in the following aspects as shown in Fig.3. 


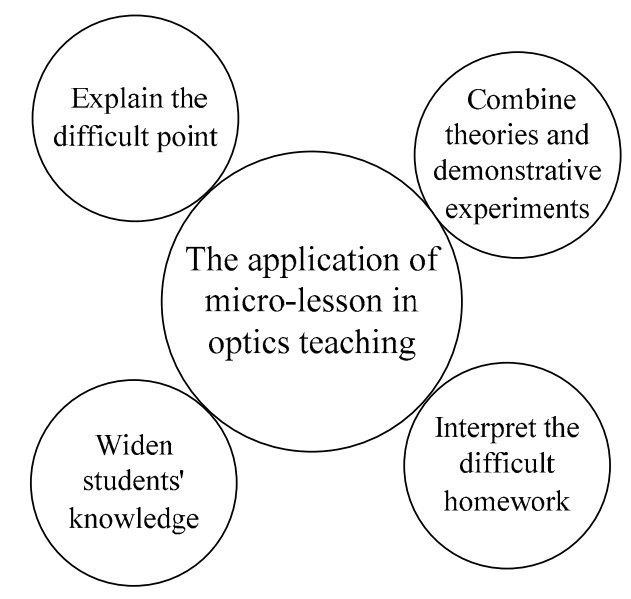

Fig.3 The application of micro-lesson in optics teaching

Firstly, widen students' knowledge. The task of optics teaching is not only passing on classical theory but also for new technology. In traditional classes, teachers just can introduce simple knowledge beyond textbook, and ways to teach just through pictures or language. If the micro-lesson is adopted, students can get more information through the short video. For example, in the year 2016, American researchers find the gravitational wave, and students will be very interested in this problem. As the demonstration process for the nonexistence of the Ittai using Michelson interferometer, is similar to the experiment which found gravitational wave. For this situation, teachers can make a micro-lesson about Michelson interferometer and gravitational wave, including experiment process and theory analysis, which can stimulate students' interests and extend their knowledge.

Secondly, explain the difficult point. Some contents are hard to understand, such as polarization and spectrum. This kind of knowledge needs students to imagine, which adds the degree of study difficulty. In this situation, teachers can play good micro-lesson videos about the difficult point. Student and teachers can both learn much from these videos.

Thirdly, combine theories and demonstrative experiments. In optics teaching, the experiment plays an important role. Many theories will be more easily understood when the corresponding demonstrative experiments can be shown simultaneously, such as optical interference and optical diffraction, but most of the experimental equipment cannot be moved to the classroom for teachers' demonstration. In traditional classes, teachers usually show students some pictures of experiment results, which is unimpressively. In order to make teaching effects better, teachers can make each experiment a micro-lesson. In the video, teacher can perform the experiment with necessary explanation. After watching videos, students can see the steps of the experiment, the process of the experiment and the results of the experiment intuitively, which can short the distant between the laboratory and the classroom. This experiment video can help students understand the corresponding theoretical knowledge and can let students experience the process of science exploration through experiments.

Fourthly, interpret the difficult homework. Optics course has many exercises, so teachers need to make necessary explanation in class time. However, students have different understanding ability, i.e., for the same exercise, some students feel it is very easy but some students feel it is very hard. Thus, it is difficult for teachers to find an appropriate method that can meet all students' need. Micro-lesson can solve this problem. Teachers can make one video for one exercise, which including the exercise itself, the theory used in the exercise and the steps to solve this exercise. Students can watch the video for many times when needed.

\section{CONCLUSION}

Micro-lesson can be a good assistant of optics teaching. We should do further research on which content can be chosen to make a small video, how can we make a good video and how can we integrate micro-lesson into traditional optics teaching. Carrying forward the advantages of micro-lesson and finding problems in micro-lesson teaching will last for a long time, we should do more work. 


\section{Acknowledgments}

This work is supported by the educational reform project of Chongqing University of Posts and Telecommunications (Grant No: XJG1615)

\section{REFERENCES}

[1] EDUCAUSE." 7 things you should know about Microlectures, " $<$ https://library.educause.edu/resources/ 2012/11/7-things-you-should-know-about-microlectures > (1 November 2012).

[2] Hu T. s., and Zhou X. Q.,"'Current Situation Analysis and Development Strategies of the Micro-lecture Construction in Universities," Modern Educational Technolog, 24(2), 5-13 (2014).

[3] Shieh, David.,"These lectures are gone in 60 seconds," Chronicle of Higher Education, 26,1-13 (2009).

[4] Shen, H.H., "To improve the efficiency of mathematics learning through the micro," College entrance exam, 12,6364 (2014).

[5] Yu, G., "The application of the micro class in the in higher vocational oral English teaching," Examination weekly, 98, 87-88 (2014).

[6] Yu, L.J., "The design and application of Micro class in junior middle school science curriculum - taking the internal energy of object teaching as example," Primary and middle school teaching, 5, 47-49 (2015). 